\title{
Effects of Different Cultivation Methods on Yield of Purple Yam
}

\section{Liu Pangyuan, Song Shuhui, Zhang Baohai, He Weiming, Wang Wenqi}

National Engineering Research Center for Vegetables, Beijing, China

\section{Email address:}

liupangyuan@nercv.org (Liu Pangyuan)

\section{To cite this article:}

Liu Pangyuan, Song Shuhui, Zhang Baohai, He Weiming, Wang Wenqi. Effects of Different Cultivation Methods on Yield of Purple Yam. Science Discovery. Vol. 4, No. 3, 2016, pp. 173-175. doi: 10.11648/j.sd.20160403.13

Received: January 11, 2016; Accepted: May 16, 2016; Published: July 5, 2016

\begin{abstract}
Purple yam (Dioscorea alata L.) belonging to the herbaceous vine plants, dioscorea genus, Dioscorea subject and one kinds of edible plants. It's Native to tropical Asia, purple yam is plants grown under a suitable short sunshine growth environment, is a kind of thermophilic plants, mainly temperate zone in China's southern provinces. We performed different cultivation methods on Yield and variety comparison test for planting on north area of China. To choicing the different position of the yam block, shuch as the top and the middle block and different weight of harvested. Then average per mu 2600 strains were calculated and counting the per mu yield. The growth of the top position of the yam is better than the middle of plant growth. The yield of the top position is higher than the same weight of tubers of the middle position. The best kind of potato weight should be between 100-150g, so that it can reduce costs, but also have a considerable income.
\end{abstract}

Keywords: Purple Yam, Cultivation, Yield

\section{紫山药不同栽培方法对产量的影响}

\section{刘庞源, 宋曙辉, 张宝海, 何伟明, 王文琪}

国家蔬菜工程技术研究中心，北京，中国

\section{邮箱}

liupangyuan@nercv.org（刘庞源）

\begin{abstract}
摘要：紫山药（Dioscorea alata L.），又名大薯、参薯、脚板薯、紫莳药、紫淮山。原产亚洲热带地区，属草本 蔓生性植物, 薯蓣科薯蓣属参薯种食用植物。紫山药是一种适宜短日照生长环境下生长的植物, 是一种喜温类植物, 主要分布在中国南方沿海诸省的温暖地带。为了在中国北方地区进行推广，我们进行了不同的栽培方式对产量影响 及品种间差异的比较试验。选择龙头和薯块中间部位及不同重量进行比较。对收获的种薯, 按每种 10 株, 平均薯块 大小进行测量，再计算每种平均区域的产量，按每亩 2600 株计算，最后折合亩产量。从生长情况看龙头部位比薯块 中段植株生长势好, 同等重量的薯块龙头部位比薯块中段的产量略高; 从中段种薯大小上看, 不一定种薯大的, 产 量就高, 种薯小的, 产量不一定就低于种薯大的。总之, 最佳种薯重量应在 $100 \mathrm{~g}-150 \mathrm{~g}$ 之间, 这样既可降低成本, 又可有相当收益。
\end{abstract}

关键词: 紫山药, 栽培, 产量 


\section{1. 前言}

紫山药（Dioscorea alata L.），又名大薯、参薯、 脚板薯、紫莳药、紫淮山。原产亚洲热带地区, 属草本蔓 生性植物, 薯蓣科薯蓣属参薯种食用植物。紫山药是一种 适宜短日照生长环境下生长的植物, 是一种喜温类植物, 主要分布在中国南方沿海诸省的温暖地带, 如浙江、江西、 广东、广西、福建、海南、江西、云南、湖南、台湾等地, 以及印度尼西亚诸岛, 另外南非洲也有作为粮食作物大面 积栽培。其营养及药用价值除具有普通山药的优点外, 还 富含花青素, 适于食用、药用和加工利用 [1] [2]。近年来, 随着人们对身体健康和营养保健的关注，对紫色作物有高 度的青睐, 特别是对紫山药这种药食同源、极具营养价值 食品高度喜爱。

中国地域辽阔, 南北气候差异较大, 南方以热带季风 气候和亚热带季风气候为主, 夏季炎热多雨, 冬季热带季 风气候区域气候温暖, 沿海地区为温带季风气候, 全年降 雨集中在夏季, 温差较小。中国北方地区主要是温带大陆 性气候, 冬季寒冷, 夏季温热。气温年较差大, 气温日较 差亦大。降水量少, 而且季节分配不均, 集中在夏季。日 照时间长, 太阳辐射强。紫山药以前在中国南方只是在农 户家房前屋后零散种植, 极少有大面积栽培, 种植也较随 意, 很少有精心的管理, 产量较低。我们把紫山药资源引 进到中国北方, 如何让紫山药适宜北方地区的生长, 并且 根据中国北方的气候特征, 提高种植产量, 提高收益, 让 更多的百姓市民认识和了解紫山药, 尽快的让紫山药走进 百姓的餐桌, 这些成了我们主要的研究内容 [3] [4]。

就以上的问题和要求, 我们进行了不同的栽培方式对 产量影响及品种间差异的比较试验。

\section{2. 试验方法和过程}

\section{1. 材料和方法}

\subsection{1. 供试材料}

我们共引进紫山药资源13份, 经过几年的栽培试验, 笁选出适宜北方地区生长的 3 个品种资源, 分别为京紫 1 号, 京紫 2 号, 京紫 3 号。我们选定京紫 2 号, 作为不同栽 培方式提高产量的试验材料。

\subsection{2. 试验地点} 植。

国家蔬菜工程技术研究中心四季青试验农场露地种

\section{2. 试验方法}

\subsection{1. 催芽}

紫山药生长期较长, 在春季中国南方气温比北方高出 10- $20^{\circ} \mathrm{C}$, 在南方三月中下旬直接栽种薯块, 十一月开始 到十二月底前可持续收获。在北方为延长生长期, 提高产 量, 露地四月中下旬种植, 最好提前催芽, 十月底收获, 可延长生长期 $35-40$ 天。
催芽方法是将选好的块茎切成长约 $6^{\sim} 10 \mathrm{~cm}$, 每个块茎 都应带有顶芽, 并将切好的块茎用草木灰沾种或用药剂浸 种的方式给紫山药栽子消毒, 并太阳下暴晒 $1^{\sim} 2$ 天, 按规定 的株行距和一定方向摆放, 表面覆盖一层薄土, 做到安全 栽种。

育苗移栽应选择温室, 底部施肥, 上部撒入 5 $6 \mathrm{~cm}$ 厚的 无菌土, 以利于提高温度。块茎处理同上。于 3 月底 4 月初 在温室内排种育苗, 注意通风和高温烧苗, 移栽前要炼苗 $2 \sim 3 \mathrm{~d}$, 待苗高 $3 \mathrm{~cm}$ 即可起苗移栽。

\subsection{2. 种植紫山药的地块选择}

紫山药喜阳光充足, 喜肥怕涝, 适宜种植在土层深厚、 有机质丰富、疏松肥沃, 向阳、地势较高、排水良好的砂 质壤土, 种植紫山药的土壤不宜采用完全沙土, 否则漏肥 漏水严重影响商品价值, 洼地黏地不宜种植, 也不适连作 或与高秆作物临作，一般间作时间 $3 \sim 5$ 年。播种前 1 周每 亩均匀施入充分腐熟的有机肥4000-5000公斤, 精细整地, 垄栽模式并按照垄宽 $85 \mathrm{~cm}$, 垄高 $30-40 \mathrm{~cm}$ 的标准

紫山药对土壤的适应性较广, 沙壤土最为适宜, 尤其 是在土层深厚、肥沃、地下水位低, 排水良好的土壤, 紫 山药要能获得优质高产。

按照紫山药对土壤的要求, 对此实验我们选择在中国 北京顺义大孙各庄地区进行栽培试验。

\subsection{3. 不同重量及不同部位种薯的选择对产量的影响试 验}

在种薯选择上采取龙头部位及薯块中后部分区分, 重 量按 $200 \mathrm{~g}, 150 \mathrm{~g}, 100 \mathrm{~g}$ 分别切成不同大小的薯块作为种薯。 每种种薯取薯 30 块, 以 10 块为一组, 分三组, 共十八组进 行对比实验。种植方法以起垄式栽培, 每六组即龙头部位 $200 \mathrm{~g}, 150 \mathrm{~g}, 100 \mathrm{~g}$; 薯块中后部 $200 \mathrm{~g}, 150 \mathrm{~g}, 100 \mathrm{~g}$ 各 10 株, 每种 60 株为一个区域, 共分 3 个区域进行试验。

\section{2. 4. 起垄式和凹沟式栽培对产量的影响试验}

在整地种植方式上采取起垄和凹沟式栽培, 品种选择 京紫 2 号。一种方式是在土地进行旋耕整平后, 起垄垄高 40公分, 行距70公分, 株距30公分进行种植; 另一种是在 平整的地面上开沟, 沟深 40 公分, 沟宽 25 公分, 把土壤翻 起, 使土壤疏松, 然后回填15公分左右, 放入种薯薯块, 再覆盖 5 公分厚的土壤, 每 60 株为一个区域, 共分 3 个区域 进行试验。

\subsection{5. 起垄式和凹沟式栽培对产量的影响试验结果}

从收获普遍结果看, 起垄式栽培薯块平均长度略长于 凹沟式栽培, 平均单薯重略高于凹沟式栽培。平均亩产高 于凹沟式栽培百分之二十左右。

综上所述, 紫山药在中国北方种植, 不仅和气候、土 壤有关, 还和栽培方式有密切关系 [7] [8]。要想获得紫山 药在北方地区种植高产 [9], 优先选择肥沃的沙壤土地, 有条件提前温室育苗, 延长生长期, 采取起垄式栽培, 底 肥充足, 种薯薯块重量在 120 克左右, 这样既降低成本又 保证植株生长旺盛, 才能获得高产。 


\section{3. 数据处理}

所有数据采用EXCEL软件进行各项数据分析、比较, 分析篮选出特性较为突出的品种。

\section{3. 结果与分析}

\section{1. 种薯不同部位不同大小对产量影响结果}

对收获的种薯, 按每种10株, 平均薯块大小进行测量, 再计算每种平均区域的产量, 按每亩 2600 株计算, 最后折 合亩产量 (见表一)。从生长情况看龙头部位比薯块中段植 株生长势好, 枝叶繁茂, 结薯块多, 同等重量的薯块龙头 部位比薯块中段的产量略高; 从中段种薯大小上看, 不一 定种薯大的, 产量就高, 种薯小的, 产量不一定就低于种 薯大的。详细调查数据见表一。

同等重量的种薯, 龙头部位比薯块中段的种薯产量要 高, 种薯块大的, 虽然产量略高, 但种植成本高, 最佳种 薯重量应在 $100 \mathrm{~g}-150 \mathrm{~g}$ 之间, 这样既可降低成本, 又可有 相当收益。

表一 不同重量及不同部位种薯的产量统计。

\begin{tabular}{llll}
\hline 种薯类型 & $\begin{array}{l}\text { 平均单块薯 } \\
\text { 重 }(\mathrm{kg})\end{array}$ & $\begin{array}{l}\text { 区域平均产 } \\
\text { 量 }(\mathrm{kg})\end{array}$ & $\begin{array}{l}\text { 预计平均亩产 } \\
\text { 量 }(\mathrm{kg})\end{array}$ \\
\hline 龙头部位 $200 \mathrm{~g}$ & 0.671 & 10.065 & 2616.9 \\
龙头部位 $150 \mathrm{~g}$ & 0.553 & 9.954 & 2480.4 \\
龙头部位 $100 \mathrm{~g}$ & 0.531 & 9.027 & 2347.02 \\
薯块中断 $200 \mathrm{~g}$ & 0.501 & 8.016 & 2084.16 \\
薯块中断 $150 \mathrm{~g}$ & 0.48 & 8.64 & 2246.4 \\
薯块中断 $100 \mathrm{~g}$ & 0.46 & 7.36 & 1913.6 \\
\hline
\end{tabular}
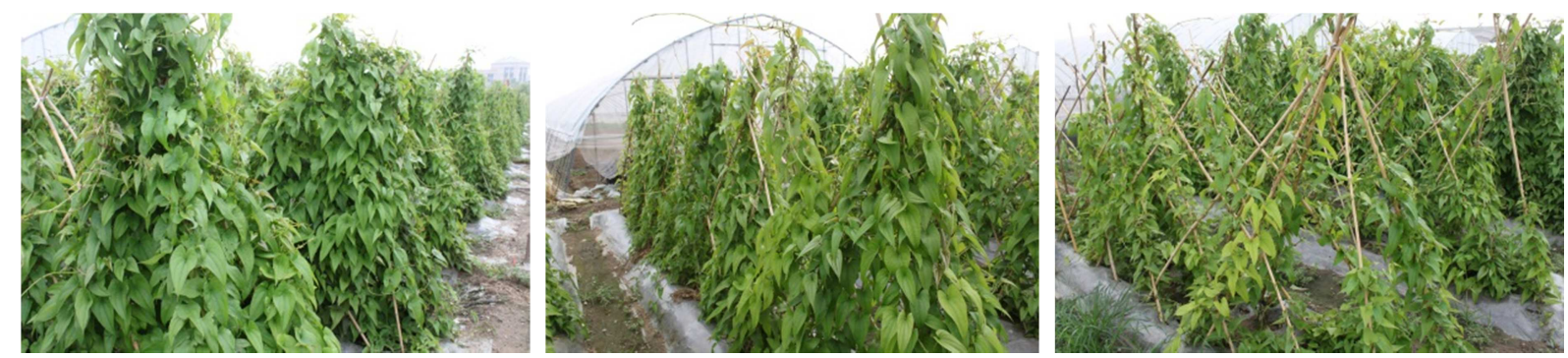

图一 不同部位的种薯生长情况。

\section{2. 讨论}

本实验也只限于国家蔬菜工程技术研究中心实验农 场和顺义地区, 紫山药在中国北方种植, 不仅和气候、土 壤有关, 还和栽培方式有密切关系 [5] [6]。要想获得紫山 药在北方地区种植高产, 优先选择肥沃的沙壤土地, 有条 件提前温室育苗, 延长生长期, 采取起垄式栽培, 底肥充 足, 种薯薯块重量在120克左右, 这样既降低成本又保证 植株生长旺盛, 才能获得高产。但对于不同区县不同土质 应该也有不同效果, 还有待进一步试种和推广 [10]。品种 产量到底和紫山药品种、土壤性质、种薯大小, 肥水大小, 气候条件及栽培技术哪一个条件相关性更大还需进一步 研究。

\section{参考文献}

[1] 唐区林, 崔否, 高先爱, 夏秋梅; 黄石地区紫山药浅生定向种 植示范及技术经验;农村经济与科技, 2015.01

［2］许海生; 紫山药的高产高效栽培技术; 农业科技通 讯;2013.03
［3］黄晓伟, 刘香荣, 胡文君; 山药高产高效栽培技术; 现代农业 科技;2013(20)

[4] 朱祺, 郑健, 王碧琴, 刘腾云, 余发新; 紫山药栽培技术研究 进展;江西科学;2014 (06)

[5] 吴丽霞, 阮静元, 高贵林, 母秀芳, 余健; 紫山药高产栽培; 云 南农业;2014. 10

６］董顺旭, 侯夫云, 张海燕, 李爱贤, 张立明, 王庆美, 解 备涛; 山东省紫山药高产栽培技术; 农业科技通讯. 2015. 1

[7] 赵永涁, 卢秀友, 江景勇; 5个紫山药地方品种比较试验; 浙江农业科学. 2013. 11

８］何圣米, 潘广敏, 汪芽芬; 紫山药丰产栽培技术. 长江蔬 菜; 2011.1

[9] 史新敏, 唐 君, 赵冬兰; 苏北地区块状菜用紫山药高效栽 培技术规程;农业科学;2009. 3

[10］毛德富, 周昌南; 紫山药在山区高产栽培技术初探;江西农 业学报;2006, $18(5): 135$ 